\title{
The Effects of Teacher's Use of Interactional Strategies on EFL Students' Speaking Performance
}

\author{
Nguyen Thanh Nha ${ }^{1}$, Phuong Hoang Yen ${ }^{2}$ \\ ${ }^{1}$ Bachelor, School of Foreign Languages, Can Tho University, Vietnam \\ ${ }^{2}$ Doctor, School of Foreign Languages, Can Tho University, Vietnam
}

\begin{abstract}
This paper reports an experimental study to investigate whether Interactional Strategies (ISs) have any significant effects on English as a Foreign Language (EFL) students' speaking performance. The study is defined as amixed-method research with two research instruments namely speaking tests and semi-structured interviews.Twenty-five participants were divided into 2 groups namelya control group and an experimental group. Theintervention was implementedfor ten weeks. The findings show that there was no significant difference about speaking performance between the control group and the experimental group although there was a significant difference in oral performance mean score of the pre-test and post-test given to both groups. Moreover, the majority of the participants in the experimental group held positive attitudes toward the teacher's use of ISs in improving their speaking performance. Implications for practical applications of Interactional Strategies are also presented.
\end{abstract}

Keywords-effects, Interactional Strategies, speaking performance, attitudes

\section{INTRODUCTION}

Mastering speaking skills is considered as a compulsory area in English language education as well as in the popular English proficiency tests such as B1-VSTEP (Vietnamese Standardized Test of English Proficiency). However, in the context of Vietnam, in which English is a foreign language, teachers usually face with non-effectively interactive classrooms (Tomlinson \& Bao, 2004; Lap \& Thy, 2017). As a result, the reasons why Vietnamese learners of English are not strong at using English could be their lack of opportunities for interaction in English classes as well as their lack of awareness about interactional strategies. Therefore, opportunities for classroom interaction should be maximized efficiently in Vietnamese EFL classes resulting learners' communicative competence. Research into classroom interaction indicated that it plays a vital role in enhancing learners' development of communicative competence (Swain, 1995; Lucha \& Berhanu, 2015). In the light of Output Hypothesis (Swain, 1995), second language learners can test out their assumptions about the target language rules, become fluent, and extend their inter-language discourse (Swain, 1995; Ellis, 2003). To deal with challenges in enhancing learners' speaking skills, it is necessary for learners to be afforded the interactional opportunities to modify their output and extend their interlanguage system (Ellis, 2015). Moreover, Zhang (2009) found that Interactional Strategies (ISs) have influences on the quality of students' performance. Besides, there is little research about learners' attitude towards the teacher's use of certain ISs on the development of their speaking ability.

Consequently, to fill the research gap felt to be existing concerning the role of teacher's use of ISs in improving learners' speaking performance in the Vietnamese context, this study attempts to achieve two research aims. The first aim is to test the effects of the teacher's use of ISs on EFL students' speaking performance. The second aim is to investigate learners' attitude towards the teacher's use of ISs in speaking class. To achieve two research aims, the study attempts to answer two research questions:

(1) What are the effects of teacher's use of Interactional Strategies on EFL students' speaking performance?

(2) What are EFL learners' attitudes towards teacher's use of Interactional Strategies? 


\section{A. Speaking performance}

\section{Literature ReVIEW}

Howarth (2001) and Abd El Fattah Torky (2006) defined speaking as a two-way process including a true communication of opinions, information, or emotions as well as showing the various functions of language. In this study, the term "speaking" is defined as the uniquely human ability to communicate information, ideas, and emotions to others using oral language. There are some problems for the speaking skill that teachers can pay more attention to help students speak effectively in the classroom. These include inhibition, lack of topical or linguistic knowledge, low participation, and mother-tongue use (Tuan \& Mai, 2015).There are several elements of speaking skill which learners need to consciously develop. According to Mazouzi (2013), learner speaking activities should be planned based on the equivalence between fluency and accuracy achievement. Hedge (2000) expressed that fluency is the ability to answer coherently by linking the words and phrases, pronouncing the sounds clearly, and using stress and intonation appropriately. According to Thornbury (2000) (cited in Deny, 2012), speaking English accurately means speaking without or with few errors on not only grammar but also vocabulary and pronunciation.

Speaking is one of the most integral elements of the curriculum in language learning and teaching, which makes it an important object of assessment as well. Knight (1992) claimed the important role of speaking assessment although it is challenging because there are so many factors that influence our impression of how well someone can speak a language, and because test scores are expected to be accurate, reliable and appropriate for teacher's purpose.

\section{B. Interactional Strategies}

Interaction is also defined as social behavior that is the collaborative exchange of thoughts, feelings, or ideas between two or more people (Brown, 2000). Lucha \& Berhanu (2015) defined classroom interaction (CI) as a collaborative process to exchange ideas, opinions or emotion among members in the classroom. Particularly, Ellis (1991) emphasized that CI is all communication including teacher-students exchanges within the classroom. Therefore, in the scope of this study, CI is considered a give-and-take process of negotiating of meanings and exchanging feedback among the teacher and learners, and among the learners within the classroom.

Particularly, Interactional Strategies (ISs) can be one of the learning strategies applied by students in the classroom context. ISs are used to repair the conversations when communication breakdowns occur. During the interaction, learners receive information about the correctness and incorrectness of their utterances, which provides learners with information about the communicative success or failure of their production. Nevertheless, not many teachers do understand clearly that ISs facilitate their students to negotiate using the language in which it can create good attitudes among students in practicing speaking.

It is critical to examine what skills the B1 speaking test aims at testing and measuring. The test assesses learners' ability toa) describe special events in the past as well as hobbies or passions in the future and briefly give reasons and explanations; b) present the situation and discuss the reasons for their best choice, as well as compare and contrast the choices; c) develop different sub-skills in speaking. Besides, it is necessary to analyze the evaluation criteria in oral production for level B1 accordingly to the Common European Framework of Reference (CEFR) for languages. To relate the evaluation criteria of the CEFR for language competences, the researcher believed that to equip learners with appropriate strategies to deal with the test, it is vital to develop students' abilities toa) express their ideas and clarify or explain the information; b)indicate their understanding by differentiating the way of addressing the same thing; c)expressing agreements and disagreements with reasoning; and d)offering an example to make one's point clear. Logically, to develop these abilities, the researcher suggests the ISs that should be used to facilitate the development of those abilities include:

1) Clarification request which is designed to elicit clarification of the interlocutor's preceding utterances.

2) Overt indications of understanding: Indicating what a speaker has understood in a particular message.

3) Overt indications of agreement: Indicating what a speaker agrees with what his partner said.

4) Overt indications of non-agreement: Indicating what a speaker does not agree with what his partner said. 
DOI: $\underline{10.51386 / 25815946 / i j s m s-v 4 i 4 p 115}$

Volume: 4 Issue: 4

July to August 2021

https://www.ijsmsjournal.org

5) Exemplification: Offering an example to make one's point clear.

\section{Language Output and Interaction in second language acquisition}

Researchers have recognized the important role of language output and interaction in fostering second language acquisition (Swain, 1995; Long, 1996; Shehadeh, 1999; Gass, 2001; Ellis, 2003; Ellis, 2005; Wang \& Castro, 2010). Particularly, the Interaction Hypothesis (Long, 1996) states that through interactions, learners negotiate for meaning and receive feedback which pushes them to modify their language in such a way that makes it comprehensible because of the connection of interaction, comprehensible input, and output with selective attention as the facilitative conditions for SLA. Pedagogically, Ellis (2005) proposed that two of the ten principles for instructed language acquisition include creating opportunities for output and interaction in the target language. Moreover, based on the Output Hypothesis (Swain, 1985), Swain stated that learners need to have opportunities for output modifications during their interaction. As a result, second language learners can test out their assumptions about the target language rules, become fluent, and extend their inter-language discourse (Swain, 1995; Ellis, 2003). Therefore, theoretical, pedagogical and empirical arguments have confirmed that language output and interaction are potential facilitative conditions for SLA. EFL learners should be engaged in language use practice by the teacher (Ellis, 2005). However, Long (1983) showed that conversations involving non-native speakers have more kinds of modification than conversations between two native speakers. Therefore, students' perception of being "pushed" is highest when the feedback comes from the teacher, especially the non-native speakers.

\section{Attitudes towards the use of Interactional Strategies}

Eagly \& Chaiken (1998) and Van den Berg et al. (2006) suggested "attitudes" with three fundamental components: cognitive, affective, and behavioral; and this is considered as the $\mathrm{ABC}$ model of attitude. According to Vishal (2014), the cognitive component of attitudes refers to the mental process of perception, conception and beliefs about the object. The affective one refers to the feeling and emotions that one has towards an object. Finally, the behavioral component is concerned with behavioral intention or action, behavior that indicates the future tendency to act in a particular way (Wicker, 1969).

Accordingly, the framework for attitude towards teacher's use of ISs still contains Affective, Cognitive, and Behavioral components. Affective Attitude concentrates on students' feelings such as enjoyment, excitement, and confidence when the teacher uses ISs in speaking classroom. Cognitive Attitude deals with the ways students perceive the benefits of certain ISs when the teacher employs each of them in speaking English. Behavioral Attitude supplies information about the students' suggestions whether the teacher needs to keep using ISs in speaking or add any ISs during the teaching process.

\section{A. Research design}

\section{Methodology}

The study mainly followed an experimental research with a pre-test and post-test in which certain ISs are independent variables and EFL students' spoken output is dependent variable. The quantitative approach enables the researcher to control and manipulate how the participants take part in the intervention program while the qualitative makes the researcher and the participants close in contact (Lodico et al., 2010). The quantitative data was collected by employing the speaking tests to measure the effects of teacher's use of ISs on learners' speaking performance while the qualitative approach with the semi-structured interview was used to investigate learners' attitudes toward teacher's use of ISs. The study involved two groups of participants labeled the experimental group and control group, adopting pretest-posttest randomized experimental design (Mills et al., 2019). The treatment program was extended in 10 weeks. During the intervention, the control group was taught speaking in traditional ways. Meanwhile, for the experimental group, certain ISs were implemented. The implementation of ISs was monitored during the study through recording video.

\section{B. Participants}

Participants in this study involved 25 non-English majored students at Can Tho University who have been studying at a private language center. They have obtained a pre-intermediate level of English proficiency, following a 
requirement of the language center before they start the current English course. The Table I below presents the background information of the two groups. The participants also included the researcher as the instructor and another teacher of English who was invited to score the speaking tests along with the researcher. The teachers have been teaching more than three years and had got an international certificated equivalent to level five of VSTEP.

TABLE I:

THE BACKGROUND INFORMATION OF THE TWO GROUPS

\begin{tabular}{|c|c|c|c|}
\hline Group & $\begin{array}{c}\text { Number of } \\
\text { participants }\end{array}$ & \multicolumn{2}{|c|}{ Gender } \\
\hline Control & 13 & 8 males & 5 females \\
\hline Experimental & 12 & 6 males & 6 females \\
\hline
\end{tabular}

\section{Materials}

The formal face-to-face instruction for the two groups was provided by the researcher using the required material for the course - A VSTEP preparation for KIT: Speaking B1 (Ly, 2016). This course book costs the total time of 30 ninety-minute periods with fifteen selected topics. The instruction for both groups in this study involved ten topics of the course book. The total time allocated to teaching these topics was equivalent to ten weeks. Given that the proper time length for the intervention of this study to be effective should be from eight weeks to twelve weeks (Mclnerney and Elledge, 2013).

\section{Instruments}

In this research, two instruments were employed namely speaking tests and semi-structured interviews.

Two speaking tests as the pre-test and post-test were administered to collect data. They were designed to examine students' speaking performance before and after the treatment between two groups. The tests were taken from the main course book to guarantee the validity(Luoma, 2004). The tests are also checked for the reliability in Statistical Package for the Social Sciences (SPSS). To evaluate students' speaking performance, the scoring framework for speaking used in the study is the combination between the scoring scale model of Weir (1990) and the B1 Preliminary Assessment Scale of the Common European Framework of Council of Europe (2001) with four dimensions: Vocabulary and Grammar, Discourse Management, Pronunciation, and Interactive Communication.

1)Grammar and Vocabulary(25\%): Grammar here focuses on the degree of controlled simple grammatical forms, and attempts to use some complex grammatical forms. Vocabulary is defined as a set of lexemes including single words and compound words. A speaker is required to use a range of appropriate vocabulary to give and exchange views on familiar topics.

2) Discourse Management (25\%) is regarded as the extent to which stretches of language can be produced despite some hesitations. Besides, learners are offered to use a range of cohesive devices.

3) Pronunciation (25\%) is regarded as the degree to which a message can be understood. The intelligible speech will involve in various factors including accents, intonation, sentence and word stress.

4) Interactive Communication (25\%) emphasizes on the learners' ability to initiate and respond appropriately, as well as maintain and develop the interaction and negotiate toward an outcome with certain support.

Interviews are conversations between the interviewer and the interviewee with a certain purpose to gain in-depth information (McNamara, 1999). In the present study, the semi-structured interview was also adopted to collect the qualitative data because of its flexibility (Gillham, 2000). The research conducted an interview with six participants from the experimental group. Two participants who gained most after the treatment, two participants who gained least after the intervention and two participants with the average gain are selected to answer eight open-ended questions individually. Eight questions in the interview were classified into four themes including (1) attitudes 
towards the teacher' frequent use of English Interactional Strategies in class; (2) attitudes towards preferred strategies; and (3) attitudes towards each Interactional Strategy.

\section{FINDINGS}

\section{A. Learners' speaking performance before and after the intervention}

The speaking tests were used as the pre-test and the post-test to measure the speaking performance of the participants in both groups before and after the intervention. The scores of the speaking tests were ranged from 0 to 10 points. Results gained from the two tests were transferred to SPSS version 26 to investigate participants' speaking performance. After that, Scale Tests were run to check the reliability of these tests. The result of the Scale Tests shows that the reliability of the pre-test and the post-test was acceptable $(\alpha=0.95, \alpha=0.91$ respectively). Accordingly, these tests were reliable enough to be used as instruments in this research.

\section{1) Learners'speaking performance within the two groups before and after the study}

In order to identify students' changes in speaking performance, the General Linear Model (GLM) tests were carried out. Firstly, the results of control group's pre-test and post-test were collected and analyzed. With $p=0.003$, it is confident enough to conclude that the pre-test's mean score and the post-test's mean score are different. Then, the Descriptive Statistic Test was performed to identify mean score of each test. These scores are illustrated in Table II.

The results showed the difference of mean scores in the pre-test and post-test $($ pre $=7.67 ; S D=1.43, M$ post $=8.71$; $S D=0.74)(F=13.34, d f=1, p=0.003)$. The mean score of the post-test was higher than that of the pre-test. It can be concluded that after ten weeks of intervention, students' speaking performance of control group was improved.

Afterward, the General Linear Model Test was carried out to identify the difference of mean score of experimental group's pre-test and post-test $(p=0.00)$, leading to a conclusion that it was fully confident that the speaking performance of the experimental group was significantly different at the pre-test and the post-test. Later, the mean scores of the pre-test and post-test were clarified by Descriptive Statistic Test (see Table II).The mean score of the pre-test was different from post-test's mean score. (M pre $=7.53 ; S D=1.36$, M post $=8.91 ; S D=0.97)(F=54.27$, $D f=1, p=0.00)$. The result indicates that the mean score of the post-test was significantly higher than that of the pretest. After the study, the speaking performance of experimental group was remarkably increased.

\section{TABLE II:}

\begin{tabular}{|c|c|c|c|c|c|c|}
\hline \multicolumn{2}{|c}{ MEAN SCORE DIFFERENCE OF STUDENTS' SPEAKING PERFORMANCE WITHIN THE TWO GROUPS } \\
\hline \multirow{2}{*}{ Control } & Tests & $\mathbf{N}$ & Minimum & Maximum & Mean & $\begin{array}{c}\text { Std. } \\
\text { Deviation }\end{array}$ \\
\cline { 2 - 7 } & Pre-test & 13 & 3.80 & 8.85 & 7.6769 & 1.43869 \\
\cline { 2 - 7 } & Post-test & 13 & 7.20 & 9.55 & 8.7192 & 0.74876 \\
\hline \multirow{2}{*}{ Experimental } & Pre-test & 12 & 4.90 & 9.35 & 7.5375 & 1.36467 \\
\cline { 2 - 7 } & Post-test & 12 & 6.85 & 10.00 & 8.9104 & 0.97733 \\
\hline
\end{tabular}

\section{2) Learners' speaking performance on the specific features within the two groups before and after the study}

A Pair Sample T-Test was run to compare the mean scores of the four specific features within the experimental group and the control group before and after the treatment. After the intervention program, speaking ability of the experimental group in terms of all four features including Vocabulary and Grammar, Discourse Management, Pronunciation, and Interactive Communication was better than that before the research $(t=-2.767, d f=11, p=.00$; $t=-5.138, d f=11, p=.00 ; t=-5.494, d f=11, p=.00 ; t=-5.063, d f=11, p=.00$ respectively). The mean scores of the four specific features of the pre-test and post-test of the experimental group are illustrated in Figure1. This shows that there was a significant improvement in students' vocabulary, discourse management, pronunciation, and interactive communication. It was also seen that learners in the experimental group made big progress in their oral performance when the teacher employed Interactional Strategies in the speaking class. 


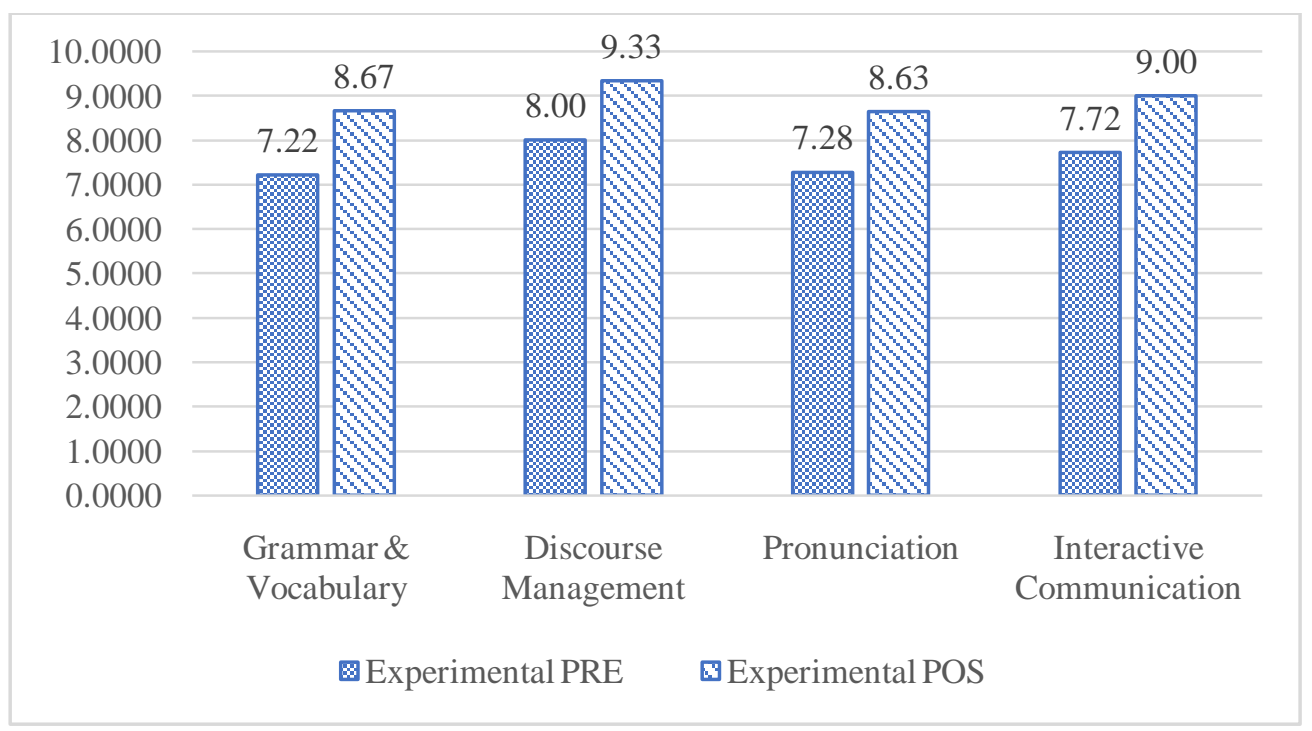

Fig 1: Mean scores on specific features of the pre-test and post-test of the experimental group

For the control group, the results indicated the difference between the mean scores on four specific features of speaking tests in terms of grammar and vocabulary, discourse management, pronunciation, and interactive communication before and after the intervention was observed $(t=-2.767, d f=12, p=.017 ; t=-3.554, d f=12, p=$ $.004 ; t=-3.074, d f=12, p=.010 ; t=-2.757, d f=12, p=.017$ respectively).

This shows that there was a significant improvement in students' vocabulary, discourse management, pronunciation, and interactive communication. On other words, the mean scores on specific features of speaking performance after the study were statistically different. In summary, although four features of speaking performance in the control group were found higher, learners in this group made small progress with a very slight change compared with the changing in experimental group. To be more specific, the mean scores of the four specific features of the pre-test and post-test of the control group are illustrated in the following Figure 2.

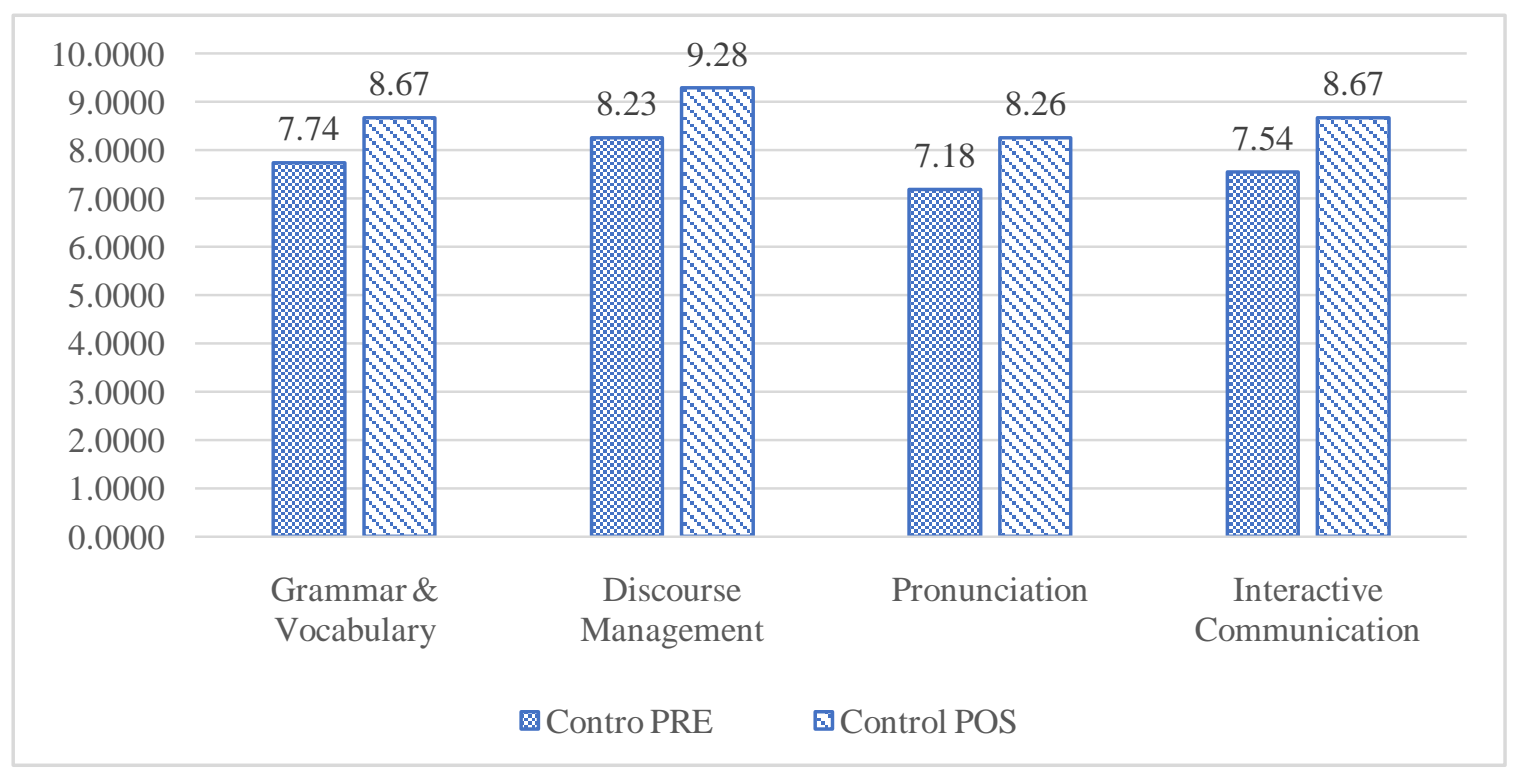

Fig2: Mean scores on specific features of the pre-test and post-test of the control group 


\section{3) Participants' speaking performance between the two groups before and after the intervention}

To evaluate students' speaking performance between the two groups before and after the intervention, the Descriptive Statistic Test, the Independent Sample T-Test and the General Linear Model Test were carried out. Firstly, the results of the Descriptive Statistic Test are presented in Table III below.

TABLE III:

STUDENTS' SPEAKING PERFORMANCE BETWEEN THE TWO GROUPS

\begin{tabular}{|l|l|r|r|r|r|r|}
\hline \multirow{2}{*}{ Test } & Group & $\mathbf{N}$ & Minimum & Maximum & Mean & $\begin{array}{r}\text { Std. } \\
\text { Deviation }\end{array}$ \\
\hline \multirow{3}{*}{ Pre-test } & Experimental & 12 & 4.90 & 9.35 & 7.5375 & 1.36467 \\
\cline { 2 - 7 } & Control & 13 & 3.80 & 8.85 & 7.6769 & 1.43869 \\
\hline \multirow{3}{*}{ Post-test } & Experimental & 12 & 6.85 & 10.00 & 8.9104 & 0.97733 \\
\cline { 2 - 7 } & Control & 13 & 7.20 & 9.55 & 8.7192 & 0.74876 \\
\hline
\end{tabular}

\section{Students' speaking performance between the two groups before the intervention}

In the pre-test, the mean score of the control group $(M=7.67)$ was a little higher than the mean score of the experimental group $(M=7.53)$. To check whether there was a significant difference in the students' speaking performance in the pre-test between the control group and the experimental group, the Independent Sample T-Test was run. The result showed that the difference in the students' speaking performance in the pre-test between the two groups was not significant $(t=-.248, d f=23, p=.806)$. This means that students' speaking performance in the pretest of two groups was the same. The two groups were distributed homogenously before the intervention.

\section{Students' speaking performance between the two groups after the intervention}

Table III also revealed that the students' speaking performance between the two groups was different after the intervention. After ten weeks of the intervention, the mean scores of the post-test of both groups were highly improved (M post $=8.71$ for the control group, $M$ post $=8.91$ for the experimental group). Figure 3 below presents the progress of both control group and experimental group.

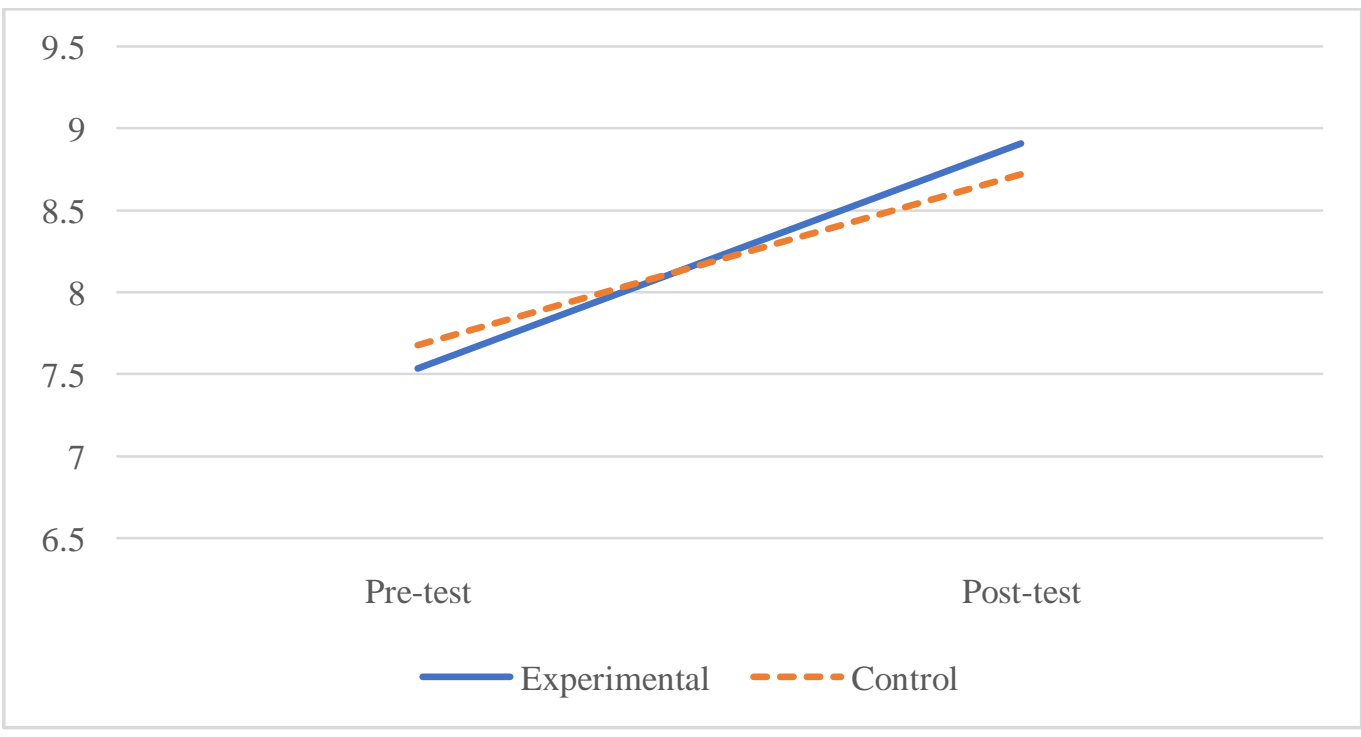

Fig 3: Summary of participant's speaking performance before and after the intervention 
It can be clearly seen from Figure 3 that there was a significant difference in speaking performance mean score of the pre-test and post-test given to both groups. Two groups' speaking performance indicated a noticeably small gap (control group $M=7.67$; experimental group $M=7.53$ ) at the pre-test. While the post-test showed a surged trend in both groups' speaking performance mean scores, it could not be denied that the post-test result of experimental group $(M=8.91)$ was a higher than control one's $(M=8.71)$. However, the result of the Independent Sample T-Test indicated that there was no significant difference between the experimental group and the control group after the intervention $(d f=23, F=.900, p=.58)$ In conclusion, the improvement of speaking performance was observed between the pre-test and the post-test of the control group and the experimental group after ten weeks. The result showed that there was no significant difference about the level of speaking performance between the two groups after the intervention.

\section{B. EFL students' attitude towards teacher's use of Interactional Strategies in the experimental group}

The researcher interviewed six out of twelve students among participants in the experimental group including two participants who gained most after the treatment (Participant A and C), two participants who gained least after the intervention (Participant B and D) and two participants with the average gain (Participant E and F) to answer eight open-ended questions individually. The aim of the interview was to identify their attitude towards teacher's use of certain Interactional Strategies in speaking class. Eight questions in the interview were classified into four themes including (1) attitudes towards the teacher's frequent use of Interactional Strategies in class; (2) attitudes towards preferred strategies; (3) attitudes towards each Interactional Strategy; and (4) learners' suggestions in using ISs in speaking class.

\section{1) Learners' attitudes towards the teacher' frequent use of ISs in speaking class(Behavioral Component in ABC Model)}

All participants strongly agreed that the teacher frequently and flexibly used all five English ISs in the three parts of the B1 English-speaking test throughout the speaking lessons, but these strategies were identified differently in every part of the speaking test by different learners. For example, Participant A, D, and F stated that:

"You used all five interactional strategies during the teaching process in speaking class. "(Participant A, interview extract)

“[...] I found that these strategies were also used extensively in every speaking lesson. ”(Participant D, interview extract)

“[...] I found that you used these five strategies while you were teaching in speaking class. ”(Participant F, interview extract)

Although it is said that the teacher used all five interactional strategies during the speaking sessions in class, participant B believed that the teacher did not use strategies of Overt Indication of Agreement and Disagreement in Parts 1 and 2, and instead these strategies were only used in Part 3.

"[...] You focused on showing agreement or disagreement, especially in some further questions in part 3." (Participant $B$, interview extract)

\section{2) Learners' attitudes towards preferred strategies (Affective Component in ABC model)}

Five out of six participants claimed that they liked the strategy of Exemplification most because giving examples for a certain topic would make the talk or the conversation more vivid and help listeners understand the topic clearer. For instance, Participant B, E, and F respectively said that:

"The examples will give me words that are close to me to make the main point clearer."(Participant B, interview extract)

"In my opinion, the strategy of giving an example is the most interesting because I find giving an example makes the problem become more obvious. "(Participant E, interview extract) 
"In my opinion, I am impressed and interested in the strategy of giving examples and clarifying the problem [...], so giving examples will make the talk become more vivid and giving examples will make the problem easier to understand and closer to me." (Participant F, interview extract)

In addition, Participant D was really interested in Overt Indication of Agreement and Disagreement strategies. He said that:

"When I present a topic, make people interact and then agree or give different points of view, I will know more about certain issues as well as when I argue with someone, this will be helpful. The listener also understands better what I mean and from there the problem will be clarified more." (Participant D, interview extract)

\section{3) Learners' attitudes towards each Interactional Strategy (Cognitive Component in ABC Model)}

Generally, the participants' responses in the interview revealed that all the participants had positive attitudes towards teacher's use of each IS in terms of grammar and vocabulary, discourse management, pronunciation, and interactive communication, which is shown below. However, there are differences in the attitudes between two participants who gained most after the treatment (Participants A and C), and two participants who gained least (Participants B and D). Particularly, greater gainers stated that they felt more confident in speaking English when the teacher used the strategy of Overt Indication of Understanding whereas limited gainers believed that thanks to the strategy Overt Indication of Agreement helped them become more confident in communicating with their teacher.

"In my speaking part, I will feel more confident, and I can speak more and express my ideas more fluently.” (Participant A, interview extract)

"When I am more confident, I will be able to express myself more and be motivated to speak more in English."(Participant $C$, interview extract)

“[...] and made me more confident in expressing that point of view. ”(Participant B, interview extract)

"When I speak and others understand, so I feel very respected and more confident."(Participant D, interview extract)

In addition, Participant B revealed that the strategy of Clarification Requests had positive effects on improving the pronunciation as well as the interactive communication between speakers and listeners, especially for those with low level of language proficiency.

"[...] when you ask for clarification, you will emphasize key words or speak slower so that I can see the main idea of the sentence clearly. Then, when you speak slowly and have a clear intonation, the pronunciation will be played more clearly." (Participant B, interview extract)

"[...], so I can also improve on my pronunciation because I can imitate the way you pronounce in some words." (Participant D, interview extract)

\section{Clarification Request}

All participants agreed that the first strategy - Clarification Request has positive effects to help them expand vocabulary and grammar structures, make the conversation comprehensible and smoother via having more opportunities to modify their spoken output, and enhance the interaction between the speaker and the listener at the same time. As Participant A, B, C, and F said:

"[...] I have to use more English words to explain what I am talking about." (Participant A, interview extract)

"[...] helps me solve a lot of problems between the speaker and the listener. If I do not understand a certain issue, the question to clarify will help our conversation become easier." (Participant B, interview extract) 
“... can know where I am wrong and correct it because I sometimes pronounce it wrong, so you cannot understand, and you will ask to clarify that problem, and correct it properly." (Participant C, interview extract)

"During communicating, I will present ideas to clarify for the listener to help the listener understand well what I am saying, and I can also add ideas to increase the fluency of the talk." (Participant F, interview extract)

\section{Overt Indication of Understanding}

Most candidates stated that strategy 2 - Overt Indication of Understanding helped them feel more confident, respected, motivated and comfortable to express their point of view in the communication process because there is the mutual interaction between the speaker and listener. For instance, Participant A, C, D, and Eagreed that:

"[...], I will feel more confident, and I can speak more and express my ideas more fluently." (Participant $A$, interview extract)

"When I am more confident, I will be able to express myself more and be motivated to speak more in English."(Participant $C$, interview extract)

“[...] helps the listener feel that they are also respected [...]”(Participant D,interview extract)

"[...] give more motivation and can develop new ideas”, “[...] usually feel very happy."(Participant E, interview extract)

Moreover, there is a difference related to the learners' attitudes towards teacher's use of Overt Indication of Understanding. Five out of six participants believed that this strategy helps them expand vocabulary and grammar structures and improve pronunciation. For instance, Participant D, E, and F agreed that:

"You show the interaction even non-verbal one, so it means you have already understood the idea, then partly this will improve your communication style, [...]”. (Participant D, interview extract)

"Because I want the person who I communicate with to understand more about that topic, I will use more vocabulary and grammar, and the pronunciation will be clearer." (Participant E, interview extract)

"About pronunciation, I also have correct pronunciation so that you can know what I am talking about and to understand better. "(Participant F, interview extract)

However, participant B claimed that this interactional strategy does not support in terms of pronunciation and has little help in enhancing vocabulary and grammar. She said:

"[...] it only supports in terms of vocabulary a little." "[...] this strategy has no effect on pronunciation." (Participant B, interview extract).

As a result, there is a consideration that the teacher should use more than one interactional strategy during the communicating process.

\section{Overt Indication of Agreement}

In strategy 3 - Expressing the agreement with the speaker's opinion, all participants believed that this strategy helps them be more confident when communicating with others because they know someone agrees with their ideas, which helps to increase the interaction of the speaker and listener in the conversation, and they also have a positive improvement in vocabulary and pronunciation. As Participant A, B, D, and E respectively said that:

"[...] because I have expressed my opinion or point of view, then listeners will agree, or they will interact with me again to let me understand that idea more deeply so that I can also show interaction." (Participant $A$, interview extract) 
"[...] about the vocabulary, I feel that it will be improved, because when you agree with me, you will also give synonyms or words close to it." (Participant B, interview extract)

"When I speak and others understand, so I feel very respected and more confident."(Participant D, interview extract)

\section{Overt Indication of Disagreement}

In strategy 4 - Expressing disagreement with the speaker's opinion, in addition to helping to improve vocabulary, pronunciation and coherence in the talk, all participants especially agreed that this strategy can help them to develop critical thinking while communicating. They strongly agreed that:

"Two people want to defend their point of view, so their opinions must be logical and more rigorous and thereby also make the talk more coherent." (Participant $C$, interview extract)

"[...] it will also give me more knowledge, as well as better critical skills. I will use more vocabulary, antonyms or synonyms, or I can compare and contrast with other issues to clarify the matter." (Participant $D$, interview extract)

"I will pay attention to your pronunciation and tone of voice, and it will support me a lot. If I use those words later, I can apply them again to improve my pronunciation." (Participant $F$, interview extract)

\section{Exemplification}

All participants were impressed with strategy number 5 - Exemplification because of the positive effects it brings, especially the improvement in vocabulary, grammar and vividness of the talk. Moreover, using some examples in real life can create an interesting learning atmosphere in classroom, which supports the learning process of learners. For example, Participant A, C, and F said that:
"In terms of vocabulary, pronunciation and grammar, I can learn a lot and I can also apply those in my speech, and it will become richer and clearer. For the classroom, the atmosphere also becomes more relaxing and happier to absorb new knowledge when the teacher uses the strategy of giving clear examples" (Participant A, interview extract)
"For example, a word that I normally pronounce incorrectly, but when I listen to the teacher give examples, I feel that it is very similar to the word I learned, but the teacher pronounces it differently, and I will have a comparison." (Participant $C$, interview extract)
"[...], then I will give an example to clarify the problem, and thus it will increase the interaction and others. After that, you can understand what I mean." (Participant F, interview extract)

In summary, all participants realized that the teacher frequently used certain ISs in speaking class, and most of them were interested in the Strategy 5 - Exemplification. In addition, participants all agreed that these ISs brought them certain benefits in terms of helping learners to gain and consolidate more vocabulary and grammatical structures, speak more fluently and correctly, improve their pronunciation and reinforce the relationship between the teacher and learners. Nevertheless, some of the respondents made three primary suggestions in using ISs in speaking class in the future

\section{Discussion}

In this section, the main findings of the current study were discussed and concluded relating to the research questions.

\section{A. The Effect of teacher's use of ISs on students' speaking performance}

The results of GLM Test for the experimental group demonstrated a significant improvement on students' speaking performance between pre-test and post-test. As a result, the findings from the research indicate that ISs were proved to be effective in enhancing students' speaking performance. Many aspects of students' speaking skill were 
improved such as vocabulary, grammatical structures, discourse management, pronunciation, and interactive communication.

It cannot be denied that there has some research worldwide on the positive effects of ISs on learners' speaking performance. Regardless of the fact that English teaching and learning environment is not similar to the English setting that the current research's participants experienced in some cases, in fact, the results illustrate to be significantly similar on the teacher's use of ISs on enhancing students' speaking performance. Therefore, it is anticipated to make some contributions to the use of ISs to some extent.

In fact, the study results generally match previous studies' findings (Mackey, 1999; Ellis \& He, 1999; Lee, 2001) in terms of improving students' speaking performance by the teacher's use of ISs. The improvement between the pretest and the post-test is attributable to what Mackey (1999) concluded that there was the link between interaction and grammatical development. It is indicated that interactional modifications during communication process could lead to second language development and more active involvement in negotiated interaction. Thus, the significant differences between pre-test and post-test depict the positive effect of ISs.

This finding is also consistent with Lee's (2001) research, in ways that ISs allowed learners to negotiate and produce more verbal language to overcome communication breakdown so that these strategies could facilitate the learners' input and output, promote second language learning and improve learners' communicative skills. The findings from quantitative data matched these viewpoints because communicative skills were one of the most successful aspects of the research.

Between the pre-test and post-test of two groups, the improvement of speaking performance was observed. Ellis \& He (1999) claimed that there was a significant enhancement from pre-test to post-test with control group and experimental group, but the experimental group' overall score was higher than the control group. However, the findings of the present study were in little disagreement with the conclusion of Ellis's study. The present findings indicated that there was no significant difference about the level of speaking performance between the two groups after the intervention. Although the post-test showed a surged trend in both groups' speaking performance mean scores, it could not be denied that the post-test result of experimental group $(M=8.91)$ was a higher than control one's $(M=8.71)$. Therefore, this fact leads to a consideration that there might have a significant difference between the experimental and control groups after the intervention if participants from both groups experienced closely similar language competence.

As a result, creating as many as opportunities to communicate in classroom interactions is necessary for language teaching and learning. Using ISs is one of the useful ways in offering learners opportunities to produce output and make the classroom an input-full environment.

\section{B. Learners' attitudes towards teachers' use of Interactional Strategies in speaking class}

All the participants of the experimental group agreed that their teacher used five intended ISs frequently and flexibly during the teaching process in speaking class, but these strategies were identified differently in every part of the speaking test by different learners. This finding was in line with Loi's (2020) perspective which believed that most of the teachers were interested in using language output and interaction activities to achieving a targeted linguistic aim.

The findings revealed that students had highly positive attitude toward the teacher's use of ISs in teaching and learning speaking skills with differently positive emotions. Particularly, the majority of students were keen on the strategy of Exemplification because giving examples helps listeners avoid communication breakdown and to make the talk more vivid and unique. This finding is quite different from the Astutik's (2017) finding, which showed that repetition was the most popular interactional strategy used by learners.

The majority of participants also agreed that ISs have positive effects to help them expand vocabulary and grammar structures, improve pronunciation, increase the interaction between speakers and listeners and improve coherence in the talk. This finding is also consistent with the research of Zhang (2009). The researcher indicated that non-native oral fluency could be gain through capable and effective input, interaction and output in EFL. Moreover, Lee (2001) 
DOI: $\underline{10.51386 / 25815946 / i j s m s-v 4 i 4 p 115}$

Volume: 4 Issue: 4

July to August 2021

https://www.ijsmsjournal.org

also found that ISs improved learners' speaking skills in terms of providing learners with a sense of confidence and interest in speaking class. It could be identified that students in the current study reported that they felt more confident and motivated in communicating when the teacher used these strategies.

Moreover, the findings showed that there were major suggestions in relation to using ISs in speaking class. Firstly, the majority of participants realized the important role of strategies of clarification requests, overt indication of disagreement and exemplification, so they stated that teacher should make full use of these strategies. Secondly, it is also necessary for the teacher to use flexibly more different kinds of ISs to support each other during the teaching process, which also helps to enhance the interactive communication in speaking class. These findings are in line with Suryati's (2015) perspectives, which focused on highlighting the importance of adopting some classroom ISs that are more facilitative to students' oral communicative competence. Finally, the teacher should consider how to use ISs appropriately with different students' language proficiency. This problem was stated by Astutik (2017), who indicated some factors that cause low learners not to use some certain ISs such as fluency, grammar, lack of vocabulary and pronunciation.

\section{IMPLICATIONS AND CONCLUSION}

The current study examined the impact of ISs on speaking performance of EFL students. From the findings of the study, the researcher gains valuable insight into the importance of using ISs to enhance oral performance among students in B1 classes. These implications are hoped to make contributions to the teaching and learning English in EFL speaking classes in general.

Firstly, the findings of the research draw a consideration that ISs show to contribute a great impact on students' speaking performance. Therefore, the EFL teachers should be aware of using ISs in teaching process. Furthermore, the research results show that it is suggested for teachers to use ISs more effectively in speaking classes.

Secondly, although the results do not show the significant difference between learning with ISs and learning with traditional ways, they indicate students' positive attitudes toward the teacher's use in learning and teaching speaking skills. It is necessary for EFL teachers to consider how ISs can be used as useful and facilitative tools to enhance the quality of teaching and learning speaking in the Vietnamese context. It can be concluded that ISs help students to learn and improve this oral skill because they used positively can facilitate students' speaking performance in many aspects such as lexical resources, grammatical structures, pronunciation, discourse management, and interactive communication. Besides, when using ISs in speaking classes, teachers should consider how to use these strategies appropriately with different students' language proficiency. For students with low English proficiency, teachers should pay more attention to choosing simple words and grammatical structures to explain the topic. For students with high English proficiency, the lessons which can be linked to the real situations seem to make these learners more interested.

Thirdly, the findings indicated that EFL learners also concern about using ISs to enhance their speaking performance. Therefore, the next implication is that EFL learners can also learn how to employ ISs to improve their own speaking performance. This study helps the learners have opportunities to reflect on their teacher's use of certain ISs on the development of their speaking ability so that they can identify some certain benefits of using ISs when communicating with others.

In conclusion, speaking, one of the most essential skills in learning a foreign language is associated with several factors such as lexical, grammar, discourse management, pronunciation, and interactive communication, so a good communicator cannot lack these factors. In this regard, employing effective strategies, especially Interactional Strategies to approach speaking teaching and learning is the utmost importance. The findings of the study reveal that students in both experimental group and control group showed a surged trend in their speaking performance mean scores, but it could not be denied that the post-test result of experimental group $(M=8.91)$ was a higher than control one's $(M=8.71)$. Additionally, after the research, students not only felt more confident, interested and more motivated in speaking but also considered Interactional Strategies as necessary strategies for learning process in speaking classes. 


\section{About The Authors}

Nguyen Thanh Nhais a teacher of English at a foreign language center in Can Tho, Vietnam. He completed a bachelor's degree of English in Education in 2018. He is currently an MA student at Can Tho University. His research interests include speaking skills and strategies, and teaching methodology. He is also keen on improving the learning experience for EFL students and applying innovative approaches for adult learners.

Phuong Hoang Yenis currently an Associate Professor at the School of Foreign Languages, Can Tho University, Vietnam. She carries studies on language teaching approaches, students' learning autonomy, self-regulated learning strategies and teachers' professional development. She published articles in different journals and is the editor of one book on formative assessment in language teaching.

\section{REFERENCES}

[1] Abd El Fattah Torky, S. (2006). The Effectiveness of a Task- Based Instruction Program in Developing the English Language Speaking Skills of Secondary Stage Students (Doctoral Dissertation, Curricula and Methods of Teaching Department, Women's College, Ain Shams University).

[2] Astutik, Y. (2017). Interactional Strategies in Public Speaking Class Used by Low Learners. Journal of English Educators Society, 2(2), 65-74.

[3] Brown, H. D. (2000). Principles of language learning and teaching. New York: Longman.

[4] Council of Europe (2001). Common European Framework of Reference for Languages: Learning, teaching, assessment. Cambridge: Cambridge University Press.

[5] Eagly, A. H., \& Chaiken, S. (1998). Attitude structure and function. In D. T.

[6] Ellis, R. \&He, X. (1999). The Roles of Modified Input and Output in The Incidental Acquisition of Word Meanings. Studies in Second Language Acquisition, 21(2), 285-301.

[7] Ellis, R. (1991). Instructed second language acquisition: Learning in the classroom. Wiley-Blackwell.

[8] Ellis, R. (2003). Task-based language learning and teaching. Oxford University Press.

[9] Ellis, R. (2005). Principles of instructed language learning. Asian EFL Journal, 7(3).

[10] Ellis, R. (2015). Understanding Second Language Acquisition. Oxford: Oxford University Press.

[11] Gass, S. M. \& Selinker, L. (2001). Second Language Acquisition: An Introductory Course, 2nd edition, Lawrence Erlbaum Associates, Inc. New Jersey.

[12] Gillham, B. (2000). Case study research methods. Bloomsbury Publishing.

[13] Hedge, T. (2000). Teaching and learning in the language classroom. Oxford: Oxford University Press.

[14] Howarth, P. (2001). Process speaking 2 Implementation. Modern English Teacher, 10(2), 34-39.

[15] Knight, B. (1992). Assessing speaking skills: a workshop for teacher development. ELT journal, 46(3), 294-302.

[16] Lap, T.Q., \& Thy, H.V.U. (2017). EFL Teachers' Challenges in Maximizing Classroom Interaction. Studies in English Language Teaching, 5(4), 695 - 709. https:// dx.doi.org/10.22158/selt.v5n44pp695

[17] Lee, L. (2001). Online interaction: Negotiation of meaning and strategies used among learners of Spanish. Recall: The Journal of Eurocall, 13(2), 232.

[18] Lodico, M. G., Spaulding, D. T., \&Voegtle, K. H. (2010). Methods in educational research: From theory to practice, 28. John Wiley \& Sons. 
[19] Loi, N. V. (2020). A Case Study of Vietnamese EFL Teachers' Conception of Language Output and Interaction. Journal of Language and Education, 6(1), 55-71. https://doi.org/10.17323/jle.2020.9777

[20] Long, M. H. (1983). Linguistic and conversational adjustments to non-native speakers. Studies in Second Language Acquisition, 5 , $177-$ 194.

[21] Long, M. H. (1996). The Role of the Linguistic Environment in Second Language Acquisition. In W. Ritchie \& T. Bhatia (Eds.). Handbook of Second Language Acquisition (pp. 413-468). San Diego, CA: Academic Press.

[22] Lucha, Z. T., \& Berhanu, A. (2015). A study on the implementation of students' classroom oral interaction in sire secondary school EFL class: Grade 10 in focus. Science, Technology and Arts Research Journal, 4(2), 294-301.https://doi.org/10.4314/star.v4i2.41

[23] Luoma, S. (2004). Assessing Speaking. Ernst Klett Sprachen.

[24] Ly, L. H. (2016). A Vstep preparation for KIT: Speaking B1. Can Tho: Can Tho University

[25] Mackey, A. (1999). Input, interaction and language development: An empirical study of question formation in ESL. SSLA, $21,557-587$.

[26] Mazouzi, S. (2013). Analysis of Some Factors Affecting Learners' Oral Performance. A Case Study: 3rd Year Pupils of Menaa's Middle Schools. (Master Dissertation, Department of Foreign Languages, English Division, Faculty ofLetters and Languages, Mohamed Khider University of Biskra, People's Democratic Republic of Algeria).

[27] McInerney, M., \& Elledge, A. (2013). Using a Response to Intervention Framework to Improve Student Learning: A Pocket Guide for State and District Leaders. Implementing ESEA Flexibility Plans. American institutes for research.

[28] McNamara, C. (1999). General guidelines for conducting interviews. Minnesota: Missouri Institute of science.

[29] Mills, G. E., \& Gay, L. R. (2019). Educational research: Competencies for analysis and applications. Pearson. One Lake Street, Upper Saddle River, New Jersey 07458.

[30] Shehadeh, A. (1999). Non-native speakers' production of comprehensible output and second language learning. Language Learning, 94(4), 627-675. https://doi.org/10.1111/0023-8333.00104

[31] Suryati, N. (2015). classroom interaction strategies employed by English teachers at lower secondary schools. TEFLIN Journal, 26(2), 247-264. https://doi.org/ 10.15639/ teflinjournal.v26i2/247-264

[32] Swain, M. (1995). Three functions of output in second language learning. In G. Cook \& B. Seidlhofer (Eds.), Principle and practice in applied linguistics: Studies in honor of H. G. Widdowson (pp. 125-144). Oxford: Oxford University Press.

[33] Thornbury, S. (2000). Accuracy, fluency and complexity. Readings in Methodology, 16, 139-143

[34] Tomlinson, B., \& Bao, D. (2004). The contributions of Vietnamese learners of English to ELT methodology. Language Teaching Research, 8(2), 199 - 222.

[35] Tuan, N. H., \& Mai, T. N. (2015). Factors Affecting Students' Speaking Performance at Le Thanh Hien High School. Asian Journal of Educational Research, 3(2), 8-23.

[36] Van den Berg, H., Manstead, A., Van der Pligt, J., \& Wigboldus, D. (2006). The impact of affective and cognitive focus on attitude formation. Journal of Experimental SocialPsychology, 42, 373-379.

[37] Vishal, J. (2014). 3D Model of Attitude. International Journal of Advanced Research inManagement and Social Sciences, 3(3).

[38] Wang, Q., \& Castro, C. D. (2010). Classroom Interaction and Language Output. English language teaching, 3(2), 175-186.

[39] Weir, C. J. (1990). Communicative Language Testing. Prentice Hall International.

[40] Wicker, A. W. (1969). Attitudes versus actions: The relationship of verbal and overt behavioral responses to attitude objects. Journal of Social Issues, 25(4), 41. https://doi.org/10.1111/j.1540-4560.1969.tb00619.x

[41] Zhang, S. (2009). The role of input, interaction, and output in the development of oral fluency. English Language Teaching, 2(4), 91-100. 